\title{
Sonochemical Approach to Synthesis of Co-B Catalysts and Hydrolysis of Alkaline $\mathrm{NaBH}_{4}$ Solutions
}

\author{
Bilge Coşkuner, Aysel Kantürk Figen, and Sabriye Pişkin \\ Department of Chemical Engineering, Yildiz Technical University, 34210 Istanbul, Turkey \\ Correspondence should be addressed to Aysel Kantürk Figen; ayselkanturk@gmail.com
}

Received 9 March 2014; Accepted 16 May 2014; Published 11 June 2014

Academic Editor: Nurettin Sahiner

Copyright (C) 2014 Bilge Coşkuner et al. This is an open access article distributed under the Creative Commons Attribution License, which permits unrestricted use, distribution, and reproduction in any medium, provided the original work is properly cited.

Co-B catalysts are promising candidates for hydrogen evolution via hydrolysis of alkaline sodium borohydride $\left(\mathrm{NaBH}_{4}\right)$ solutions. In the present paper, a sonochemical approach was investigated for synthesis of $\mathrm{Co}-\mathrm{B}$ catalysts and hydrolysis of alkaline $\mathrm{NaBH}_{4}$ solutions. Sonochemical application on synthesizing process improved the intrinsic and extrinsic properties of Co-B catalysts such as crystal, spectral, surface area, pore volume, pore diameter, and particle size. Co-B catalysts prepared by sonochemical approach possessed smaller particle size, higher surface area, and higher pore volume than the Co-B catalysts prepared by coprecipitation synthesis. The effects of sonochemical process on hydrolysis of alkaline $\mathrm{NaBH}_{4}$ solutions were investigated by Arrhenius theory. It was clearly demonstrated that the advantages of alkaline $\mathrm{NaBH}_{4}$ solution sonohydrolysis provide superficial effects on hydrogen evolution kinetic as maximum $\mathrm{H}_{2}$ generation rate (HGR) and minimum activation energy $\left(E_{a}\right)$.

\section{Introduction}

$\mathrm{NaBH}_{4}$ as a solid state hydrogen storage material for on-board hydrogen generation systems has drawn much attention due to its superficial properties as it is non-flable, nontoxic, selective, environmentally friendly, and also one of the light weight complex hydrides with high hydrogen capacity (11 wt.\%) [1$3]$.

$\mathrm{NaBH}_{4}$ is self-decomposable in aqueous solutions and can be stabilized by alkalization $[2,4]$. Hydrogen generation from $\mathrm{NaBH}_{4}$ is supplied for fuel cells by means of alkaline solution hydrolysis in contact with certain catalysts. Several researchers have been focused on homogeneous and/or heterogeneous catalysts such as acids, metal complexes, metal salts, metal alloys, and supported catalysts. Nonnoble metals, especially, have attracted significant attention in turns of both reactivity and costs. Among different nonnoble catalysts such as $\mathrm{Co}, \mathrm{Ni}, \mathrm{Cu}$, and $\mathrm{Fe}$ catalysts could be used for hydrolysis reactions of alkaline $\mathrm{NaBH}_{4}$ solutions from the view point of low cost, stability, crystallinity, and high activity [4-8].

Between all nonnoble metals for hydrogen evolution via hydrolysis of alkaline $\mathrm{NaBH}_{4}$ solutions, researchers have shown much attention to Co-B catalysts because of their prior properties. Cavaliere et al. stated that Co-B catalyst, a black solid, could be classified in two categories as cobalt boride $\left(\mathrm{Co}_{x} \mathrm{~B}\right)$ and cobalt-boron alloy $(\mathrm{Co}-\mathrm{B})$. Considering this the chemical structure of cobalt borides has been reported unclear and obtained variety of structure as $\mathrm{CoB}, \mathrm{Co}_{2} \mathrm{~B}$, $\mathrm{Co}_{3} \mathrm{~B}$, and, $\mathrm{Co}_{x} \mathrm{~B}[9,10]$. Researchers suggested that $\mathrm{XRD}$ and XPS techniques can be used to characterize Co-B structure. Furthermore amorphous Co-B catalyst is identified with a broad peak centered at around $45^{\circ}$ diffraction angle [11]. Many methods for synthesizing of Co-B catalysts including chemical reduction [12], sol-gel $[13,14]$, and wet impregnation [15] are reported in the literature.

Sonochemical approach has been performed in a large number of organic reactions. Sonowaves, that is, to say ultrasonic irradiation, are oscillating sound pressure waves with a frequency from about 20 to $100 \mathrm{MHz}$ [16]. This method has been widely used in the preparation of chemical materials such as ceramics [17], alloys [18], composites [19], and polymers [20] due to its cavitation effect on chemical process. Sonowaves enhance the chemical reaction and mass transfer via the physicochemical changes in processed medium [21, 22 ]. In addition to this, sonowaves are proven as useful technique for inhibiting particle agglomeration in chemical environments [23]. The activity of catalysts can improve by means of using of sonowaves in catalysts preparation step [24]. 


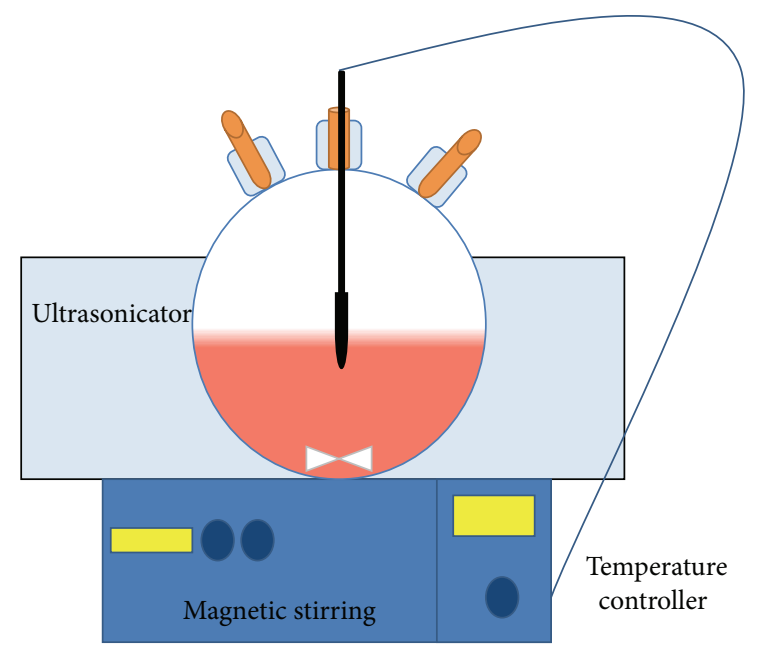

(a)

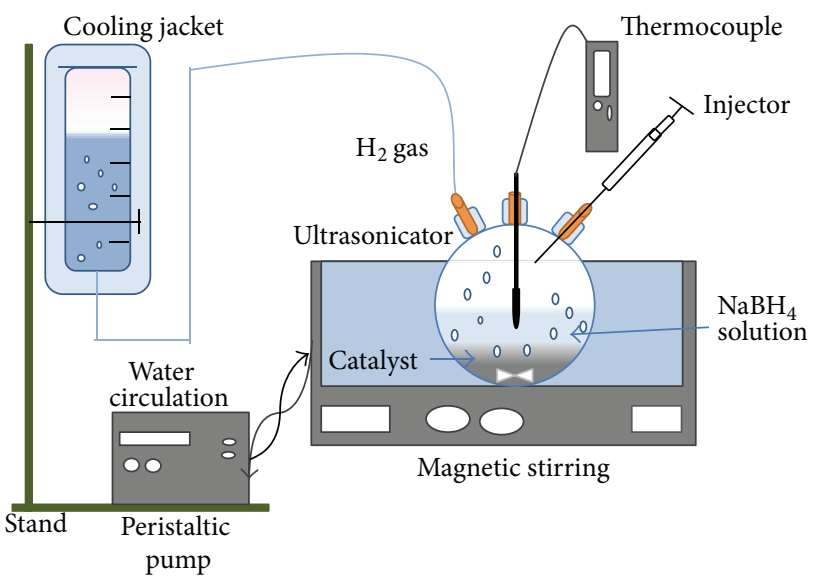

(b)

FIGURE 1: Experimental systems. (a) Coprecipitation and sono-coprecipitation synthesis system of Co- $\mathrm{B}_{\text {catalyst. }}(\mathrm{b}) \mathrm{Alkaline} \mathrm{NaBH}_{4}$ sonohydrolysis/hydrolysis system.

It has been reported that uniform spherical $\mathrm{Co}-\mathrm{B}$ amorphous alloys were prepared by ultrasound assisted $(50 \mathrm{~W})$ reduction of $\mathrm{Co}\left(\mathrm{NH}_{3}\right)_{6}{ }^{2+}$ with $\mathrm{BH}_{4}{ }^{-}$in aqueous solution in $30 \mathrm{~min}$. It is also noted that extremely extensive power or very long time is harmful for activity and selectivity due to melting [23]. Vanadium phosphorous oxide catalyst is synthesized using ultrasound irradiation in a relatively short time and its activity improved for hydrocarbon oxidation is tested [22]. Uniform Ni-B amorphous alloy nanoparticles are prepared by ultrasound-assisted reduction of $\mathrm{Ni}\left(\mathrm{NH}_{3}\right)_{6}{ }^{2+}$ with $\mathrm{BH}_{4}{ }^{-}$ in aqueous solution and the particle size is controlled by adjusting the ultrasound power. The unique characters of amorphous alloy, morphologic structure, and $\mathrm{Ni}$ active sites with higher electron density of this catalyst are crucial for its superior catalytic properties [25]. Ultrasonic hydrolysis of ammonia borane $\left(\mathrm{NH}_{3} \mathrm{BH}_{3}\right)$ with sol-gel synthesized $\mathrm{Co}-\mathrm{B}$ catalyst is firstly investigated and it is noted that hydrogen generation rate has been increased by $37.79 \%$ under ultrasonic conditions [26].

The aim of this study was to provide a sonochemical approach and investigation of effects on synthesizing of Co$\mathrm{B}$ catalysts and hydrolysis of alkaline $\mathrm{NaBH}_{4}$ solutions. For confirming this, Co-B catalysts were synthesized by two methods, as sono-coprecipitation and coprecipitation from cobalt(II) chloride hexahydride $\left(\mathrm{CoCl}_{2} \cdot 6 \mathrm{H}_{2} \mathrm{O}\right)$ and boron oxide $\left(\mathrm{B}_{2} \mathrm{O}_{3}\right)$, and hydrolysis of alkaline $\mathrm{NaBH}_{4}$ solutions were performed under sonowaves and magnetic stirring. The intrinsic and extrinsic properties of Co-B catalysts were discussed based on Brunauer-Emmett-Teller surface analysis (BET), X-ray diffraction (XRD), Fourier transform infrared spectroscopy (FT-IR), and scanning electron spectroscopy (SEM) characterizations. The hydrolysis of alkaline $0.12 \mathrm{M} \mathrm{NaBH}_{4}$ solutions were investigated under different reaction temperatures $\left(22^{\circ} \mathrm{C}-60^{\circ} \mathrm{C}\right)$ in presence of $\mathrm{Co}-\mathrm{B}$ catalysts under two different conditions. For identifying the effect of sonochemical approach on hydrolysis kinetics of alkaline $\mathrm{NaBH}_{4}$ solutions, Arrhenius theory was used to determine the kinetic parameters.

\section{Materials and Methods}

$\mathrm{B}_{2} \mathrm{O}_{3}$ (99\% purity) was supplied from Eti Mine Works General Management-Turkey. $\mathrm{CoCl}_{2} \cdot 6 \mathrm{H}_{2} \mathrm{O}$ with $97 \%$ purity, used as cobalt source, was purchased from Merck. Sodium hydroxide $(\mathrm{NaOH})$ was purchased from Labor Technic, used as stabilizer for $\mathrm{NaBH}_{4}$ solutions. $\mathrm{NaBH}_{4}$ with a minimum purity of $96 \%$ was supplied by Fluka.

2.1. Sonochemical Approach to Coprecipitation Synthesis of Co- $B$ Catalyst. The system for synthesizing the Co-B catalysts was illustrated in Figure 1(a). In synthesis of Co-B catalysts, two different methods were used. For sonochemical approach, reactor modified with ultrasonicator was used in coprecipitation synthesis of Co-B catalyst. The laboratory type ultrasonicator, that was commonly used for cleaning purpose, was selected. The ultrasonic power of the bath-type ultrasonicator (Bandelin Sonorex Super RK 255H) is $280 \mathrm{~W}$ and frequency of irradiation is $35 \mathrm{kHz}$. Self-certification of sono-co-precipitation synthesis, which was provided by coprecipitation synthesis of Co-B catalyst via reactor modified with magnetic stirring system, was used.

In synthesis of Co- $\mathrm{B}$ catalysts, firstly $0.5 \mathrm{M} \mathrm{B}_{2} \mathrm{O}_{3}$ solution was prepared and then $\mathrm{CoCl}_{2} \cdot 6 \mathrm{H}_{2} \mathrm{O}$ were added. $0.1 \mathrm{M}$ $\mathrm{NH}_{4} \mathrm{OH}$ was added by drop wise method until $\mathrm{pH}$ level of solution reached 6 . The solution was mixed for 2 hours at $85 \pm 3^{\circ} \mathrm{C}$ in reactor to obtain bulk structure. According to the procedure, ultrasonicator or magnetic stirring $(500 \mathrm{rpm})$ was applied during the Co-B catalyst synthesis reaction.

In the synthesis of Co-B catalysts, cobalt precious- $\mathrm{CoCl}_{2}$ and boron source- $\mathrm{B}_{2} \mathrm{O}_{3}$ were solved into water. $\mathrm{CoCl}_{2}$ separates into its anions and cations; by the effect of $0.1 \mathrm{M}$ 
TABLE 1: Texture properties of Co-B catalysts.

\begin{tabular}{lcccc}
\hline Code & Synthesis type & Specific surface area $\left(\mathrm{m}^{2} / \mathrm{g}\right)$ & Pore size $\left(\mathrm{cm}^{3} / \mathrm{g}\right)$ & Pore volume $(\AA)$ \\
\hline CoB-1 & sono-coprecipitation & $3.36 \pm 0.16$ & 0.0141 & 168.67 \\
CoB-2 & Coprecipitation & $1.98 \pm 0.11$ & 0.0066 & 133.39 \\
\hline
\end{tabular}

$\mathrm{NH}_{4} \mathrm{OH}$ addition, the synthesis reaction occurred as (1). The coprecipitation synthesis reaction of $\mathrm{Co}-\mathrm{B}$ compounds are given as below:

$$
9 \mathrm{Co}^{2+}+2 \mathrm{~B}_{2} \mathrm{O}_{3} \stackrel{\text { Alkali medium }}{\longrightarrow} 2 \mathrm{Co}_{3} \mathrm{~B}+\mathrm{Co}_{3}\left(\mathrm{BO}_{3}\right)_{2} .
$$

Subsequently, bulk materials were dried at approximately $100^{\circ} \mathrm{C}$ under the vacuum condition for overnight to eliminate the remaining water molecules. Moreover, forming stable structure, catalysts were calcined at $500^{\circ} \mathrm{C}$ for 4 hours in air. As a last step, Co-B catalysts were prepared for characterization of the intrinsic and extrinsic properties.

XRD patterns of Co-B catalysts were recorded using Philips Panalytical X'Pert-Pro diffractometer with $\mathrm{Cu} \mathrm{K} \alpha$ radiation in a range of diffraction angles from $5^{\circ}$ to $80^{\circ}$ with $\mathrm{Cu} \mathrm{K} \alpha$ radiation $(\lambda=0.15418 \mathrm{~mm})$ at operating parameters of $40 \mathrm{~mA}$ and $45 \mathrm{kV}$ with $0.02^{\circ}$ step size and speed of $1^{\circ} / \mathrm{min}$. The morphology and particular size of the Co-B catalysts were observed by using SEM techniques (JEOL JSM 5410 $\mathrm{LV})$. The catalysts were covered with $\mathrm{Au}$ and made ready for analysis by fixing to the device's sample holder with the help of a carbon sticky band. Surface properties of Co$\mathrm{B}$ catalysts were determined via using a surface area and porosimetry analyzer (Micromeritics ASAP 2020). Spectral properties were characterized via FT-IR (Perkin Elmer Spectrum One) with ATR accessories in the spectral range of $4000 \mathrm{~cm}^{-1}-650 \mathrm{~cm}^{-1}$ with a spectral resolution of $4 \mathrm{~cm}^{-1}$ in the transmittance mode.

2.2. Sonochemical Approach to Hydrolysis of Alkaline $\mathrm{NaBH}_{4}$ Solutions. The hydrolysis reaction of $\mathrm{NaBH}_{4}$ is as given below. Four mole $\mathrm{H}_{2}$ is generated during efficient hydrolysis reaction per mole $\mathrm{NaBH}_{4}[1-3]$

$$
\mathrm{NaBH}_{4}+2 \mathrm{H}_{2} \mathrm{O} \longrightarrow \mathrm{NaBO}_{2}+4 \mathrm{H}_{2} \text {. }
$$

Figure 1(b) shows the systems; the hydrolysis reactions of alkaline $\mathrm{NaBH}_{4}$ solutions were carried out. The $15 \mathrm{~mL}$ glass reactor was immersed in a system and connected to the water filled inverter burette in order to measure the evolved hydrogen volume. The measured data was used in investigation of hydrolysis kinetic. To compare the results of sonochemical hydrolysis, the system modified with magnetic stirrer and the same procedure was followed for magnetic stirring (500 rpm). According to the procedure, ultrasonicator or magnetic stirring was applied during the hydrolysis of alkaline $\mathrm{NaBH}_{4}$ solutions.

In the experiments, $10 \mathrm{wt} \% \mathrm{NaOH}$ alkaline $0.12 \mathrm{M}$ $\mathrm{NaBH}_{4}$ was hydrolyzed in presence of $0.5 \mathrm{mg}$ catalysts. The reactions applied in range of $22^{\circ} \mathrm{C}-60^{\circ} \mathrm{C}$ with temperature controlling system.

The kinetic investigation of sonochemical and magnetic stirring hydrolysis of alkaline $\mathrm{NaBH}_{4}$ solution was identified via Arrhenius theory. The characterization of hydrolysis reaction behavior was enlightened by zero-order, first-order, and second-order reaction kinetic models. The activation energies and rate constants were determined via Arrhenius theory $[12,26,27]$.

In literature, zero-order reaction is shown as below, model generally defined as reactant independent kinetic model. In the model, $\mathrm{C}_{\mathrm{NaBH}_{4}}$ is the concentration, $r$ is the rate of reaction, and $k$ is the reaction rate constant based on the solution volume

$$
\frac{d C_{\mathrm{NaBH}_{4}}}{d t}=-r_{\mathrm{NaBH}_{4}}=-k(T) .
$$

Equation (3) is formed as below when the integration is applied:

$$
\left(C_{\mathrm{NaBH}_{4}}-C_{\mathrm{NaBH}_{4}}\right)=-k(T) \cdot t .
$$

First-order reaction model is dependent on the reactants' concentration and its basic (5) and integration applied forms (6) are shown below:

$$
\begin{gathered}
\frac{d C_{\mathrm{NaBH}_{4}}}{d t}=-r_{\mathrm{NaBH}_{4}}=-k(T) \cdot C_{\mathrm{NaBH}_{4}} \\
\ln \left(\frac{C_{\mathrm{NaBH}_{4}}}{C_{\mathrm{NaBH}_{4}}}\right)=k(T) \cdot t .
\end{gathered}
$$

The second-order reaction model is also dependent on reactants concentration with second degree and integrated forms are shown below:

$$
\begin{gathered}
\frac{d C_{\mathrm{NaBH}_{4}}}{d t}=-r_{\mathrm{NaBH}_{4}}=-k(T) \cdot C_{\mathrm{NaBH}_{4}}^{2} \\
\left(\frac{1}{C_{\mathrm{NaBH}_{4}}}-\frac{1}{C_{\mathrm{NaBH}_{4}}}\right)=-k(T) \cdot t .
\end{gathered}
$$

\section{Results and Discussion}

3.1. Sonochemical Approach to Coprecipitation Synthesis of Co$B$ Catalyst. Co-B catalysts were synthesized via two different systems (Figure 1(a)). The CoB-1 catalyst was synthesized with sonochemical approach and CoB-2, which used as control sample, was synthesized by magnetic stirring system. The catalysts were codded according to their synthesis methods (Table 1).

Table 1 shows the textural properties of Co-B catalysts. Comparing the specific surface areas of CoB-1 catalyst with CoB-2 catalyst, the sonochemical approach a considerably increased the surface area of catalyst up to $70 \%$. With this method not only specific surface area increased but also other 

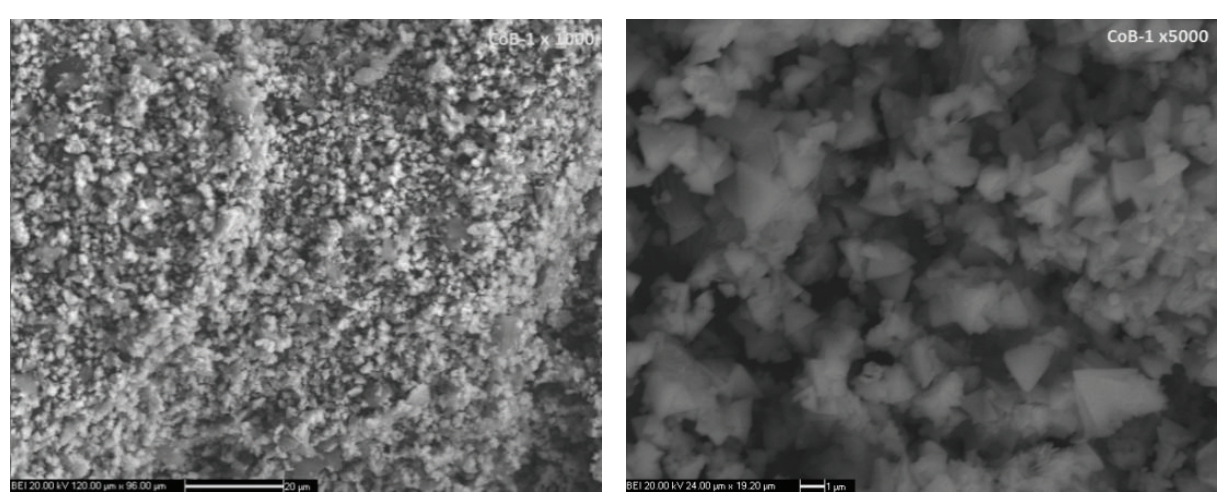

(a)
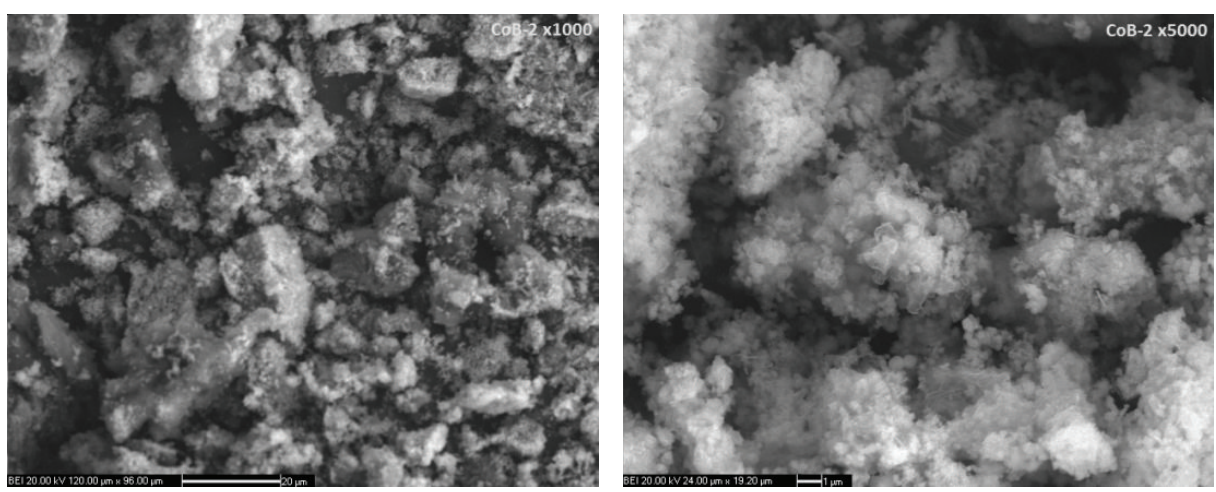

(b)

FIgURE 2: The SEM images of Co-B catalysts with $\times 1000$ (left) and $\times 5000$ (right) magnification; (a) CoB-1 catalyst, (b) CoB-2 catalyst.

TABle 2: Particle size distribution of Co-B catalysts.

\begin{tabular}{lccc}
\hline Code & $\begin{array}{c}\text { Average particle } \\
\text { size } \\
(\mu \mathrm{m})\end{array}$ & $\begin{array}{c}\text { Maximum } \\
\text { particle size } \\
(\mu \mathrm{m})\end{array}$ & $\begin{array}{c}\text { Minimum } \\
\text { particle size } \\
(\mu \mathrm{m})\end{array}$ \\
\hline CoB-1 & 1.25 & 2.77 & 0.30 \\
CoB-2 & 3.00 & 7.39 & 0.57 \\
\hline
\end{tabular}

texture properties as pore size and volume of catalysts were improved up to $114 \%$ and $26 \%$, respectively.

Figure 2 shows the SEM images of Co-B catalysts at 1000 and 5000 magnification. Particles of Co-B catalyst synthesized by sonochemical approach were homogeneously dispersed and smaller than coprecipitation synthesized Co-B catalyst.

Table 2 shows average, minimum, and maximum particle sizes were measured from SEM images. It was indicated that Co-B prepared with sonochemical coprecipitation synthesis was shown a smaller average size of $1.25 \mu \mathrm{m}$, and particle size of the catalyst was reduced up to $58 \%$ (Table 2). BET results were consistent with the SEM results.

Figure 3 shows XRD patterns of synthesized Co-B catalysts. Comparing XRD pattern of synthesized catalysts with the standard diffraction spectrum (JCPDS: 00-012-0443 and 01-073-1540), the synthesized product was crystalline $\mathrm{Co}_{3} \mathrm{~B}$ and $\mathrm{Co}_{3}\left(\mathrm{BO}_{3}\right)_{2}$. The sharpness of XRD reflections clearly

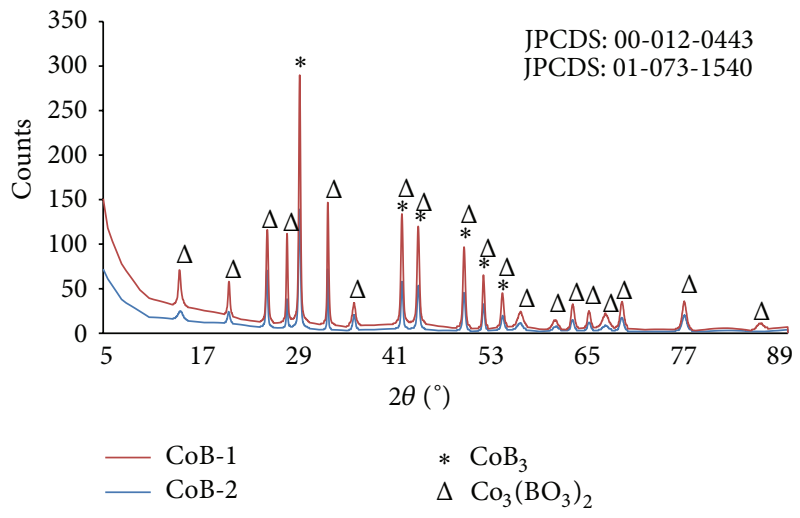

FIGURE 3: The XRD patterns of Co-B catalysts.

shows that the synthesized Co-B catalysts were highly crystalline. The characteristic peaks of phases were indexed in XRD patterns. It was clear that sonochemical treatment does not affect the crystalline phases of Co-B catalysts.

Figure 4 shows FT-IR spectrums of Co-B catalysts. In a direct comparison of the observed FT-IR spectrums of both catalysts, it was clearly seen that B-O band frequencies were detected at the same wave number regions. The bands at $3197 \mathrm{~cm}^{-1}$ and $3206 \mathrm{~cm}^{-1}$ corresponded to vibration of $\mathrm{H}$ $\mathrm{O}$ groups. The bands at $1403 \mathrm{~cm}^{-1}$ and $1350-935 \mathrm{~cm}^{-1}$ were contributed asymmetric stretching of $\mathrm{B}-\mathrm{O}$. The bands were 


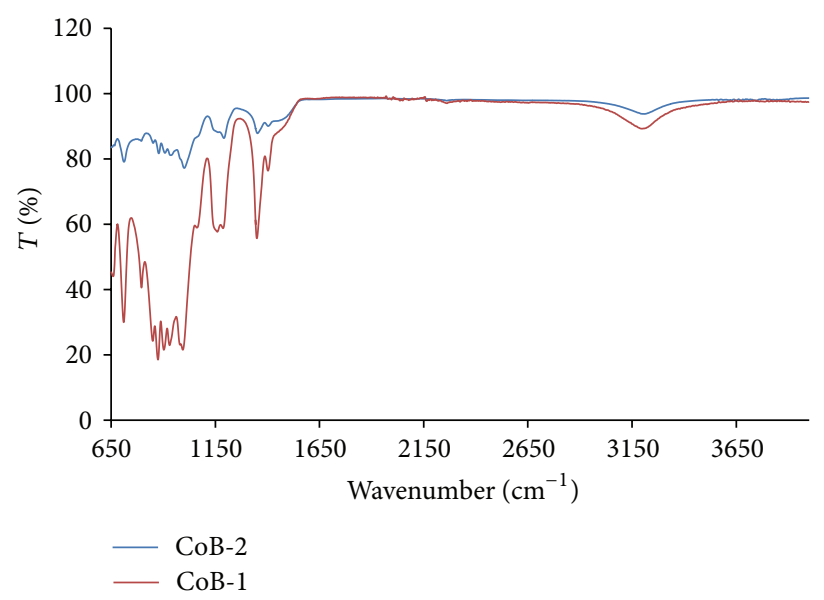

FIgURE 4: The FT-IR spectrum of Co-B catalysts.

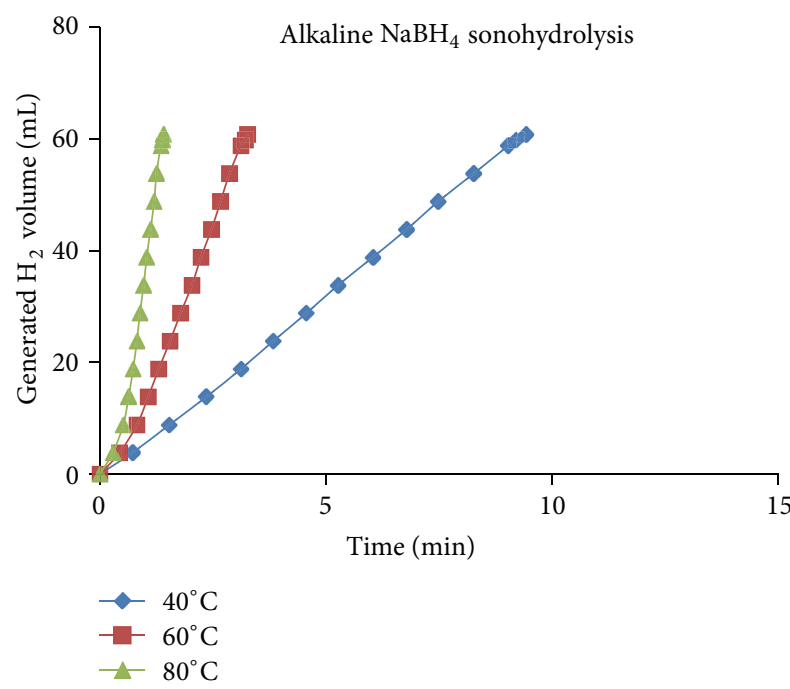

(a)

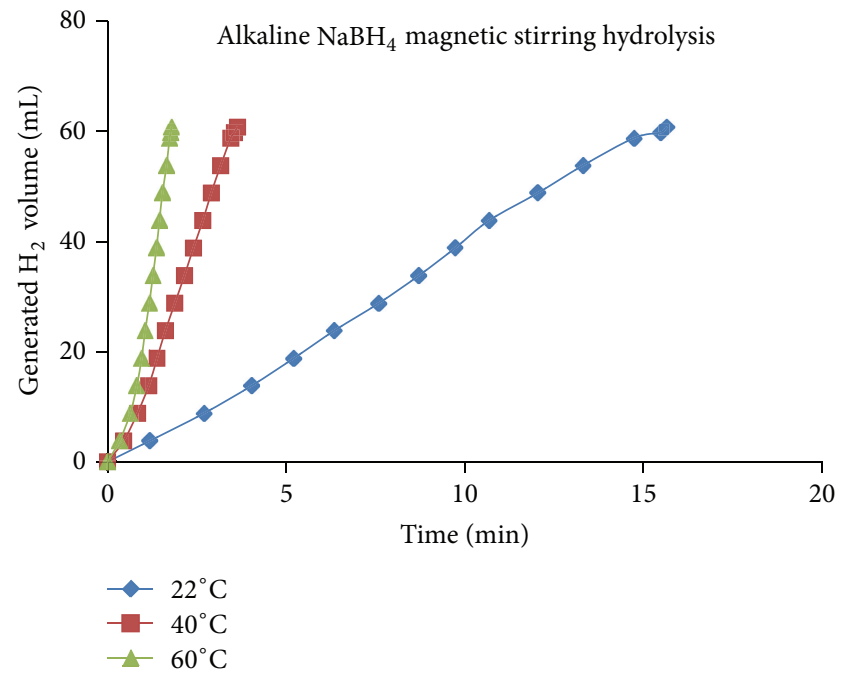

(b)

FIGURE 5: Hydrogen generation volume versus time for sonohydrolysis and magnetic stirring hydrolysis of alkaline (10 wt.\%) $0.12 \mathrm{NaBH}_{4}$ solutions in presence of $0.5 \mathrm{mg}$ CoB- 1 catalyst.

assigned between $950-870 \mathrm{~cm}^{-1}$ and $710-795 \mathrm{~cm}^{-1}$ and were symmetric stretching band of B-O [28-30].

CoB-1 catalysts, prepared via sonochemical coprecipitation synthesis, show the best intrinsic and extrinsic properties that are contributing factors to the catalytic activity. It was concluded to start sonohydrolysis of alkaline $\mathrm{NaBH}_{4}$ solutions with CoB-1 catalysts which were prepared via sonochemical coprecipitation synthesis.

\subsection{Sonochemical Approach to Hydrolysis of Alkaline $\mathrm{NaBH}_{4}$} Solutions. In order to investigate the effect of sonochemical approach, hydrolysis of alkaline $\mathrm{NaBH}_{4}$ solutions in presence of CoB-1 catalyst were carried out with two different procedures. The evaluated $\mathrm{H}_{2}$ volume versus time during the reactions was given in Figure 5. The $\mathrm{H}_{2}$ generation started immediately after catalyst contact with alkaline $\mathrm{NaBH}_{4}$ solution. As a result of this, CoB-1 catalyst did not have induction period to be active. Effect of increasing in temperature was shown in Figure 5. The $\mathrm{H}_{2}$ evolution shows direct proportion with temperature in both systems. In sonochemical alkaline $\mathrm{NaBH}_{4}$ solution hydrolysis, hydrolysis time dropped $1.40 \mathrm{~min}$ from $9.41 \mathrm{~min}$ by increasing of temperature from $22^{\circ} \mathrm{C}$ to $60^{\circ} \mathrm{C}$. The same tendency was observed in magnetic stirring hydrolysis, and reaction time decreased to $13.88 \mathrm{~min}$.

Figure 6 shows the effects of temperature and sonowaves on hydrogen generation. It was clearly seen that by comparing two different approach, sono-waves developed the hydrolysis characteristics of system via cavitation on surface of catalyst. The ultrasonic approach improved the interaction between the Co-B catalyst and alkaline $\mathrm{NaBH}_{4}$ solution and made homogeneous distribution in the alkaline $\mathrm{NaBH}_{4}$ 


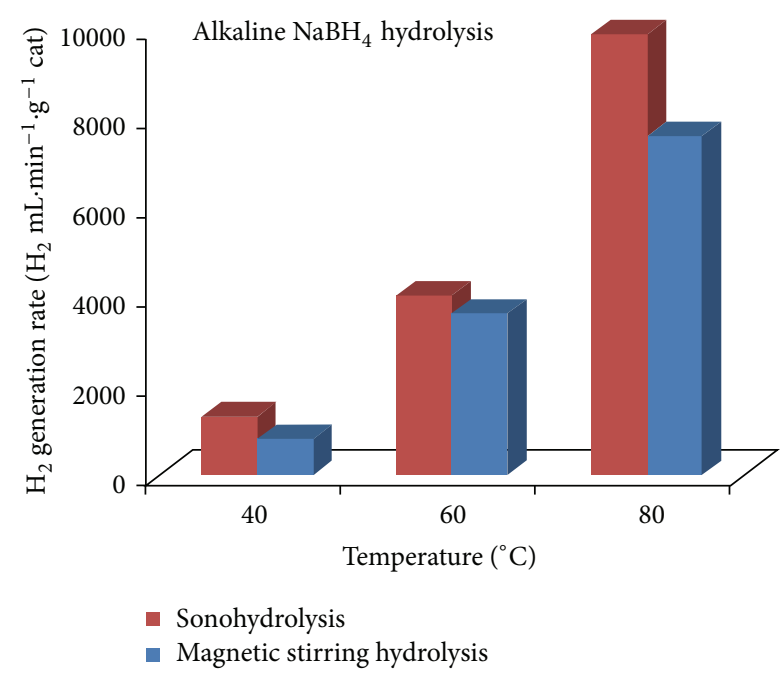

FIGURE 6: Hydrogen generation rate comparison versus temperature for sonohydrolysis and magnetic stirring hydrolysis of alkaline (10 wt.\%) $0.12 \mathrm{NaBH}_{4}$ solutions in presence of $0.5 \mathrm{mg} \mathrm{CoB}-1$ catalyst.

solution and CoB-1 catalyst. During the sonohydrolysis, cavitation bubbles created high energy effects and this caused continuous acceleration of hydrogen generation rate [19]. As can be seen, ultrasonic treatment during the hydrolysis results in maximum increase in the hydrogen generation from alkaline $\mathrm{NaBH}_{4}$ solution up to $65 \%$ at $40^{\circ} \mathrm{C}$. The authors suggest to use of sonohydrolysis instead of magnetic stirring hydrolysis for improving the hydrogen generation rate of system.

Figure 7 shows the kinetic investigation of sonochemical and magnetic stirring hydrolysis in presence of CoB-1 catalyst. The characterization of hydrolysis reaction behavior was identified by zero-order, first-order, and second-order reaction kinetic models and Arrhenius theory. As seen from Figure 7, in both hydrolysis conditions the hydrolyses of alkaline $\mathrm{NaBH}_{4}$ solutions were in compliance with zeroorder reaction kinetic model and this indicated that hydrogen generation rate was independent from concentration of $\mathrm{NaBH}_{4}$. Depending on Arrhenius theory, activation energy of sonohydrolysis of alkaline $\mathrm{NaBH}_{4}$ solution was $46.15 \mathrm{~kJ} \cdot \mathrm{mol}^{-1}$ and its Arrhenius rate constant was $19.89 \mathrm{~min}^{-1}$. For hydrolysis of alkaline $\mathrm{NaBH}_{4}$ solution, which was carried out in magnetic stirring systems, the kinetic values were determined as $51.68 \mathrm{~kJ} \cdot \mathrm{mol}^{-1}$ activation energy and $15.16 \mathrm{~min}^{-1}$ Arrhenius rate constant.

In literature, Co containing catalysts activation energies were determined and summarized in Table 3 . The activation energies of Co containing catalysts show variety; for example, Copowder $\left(75.00 \mathrm{~kJ} \cdot \mathrm{mol}^{-1}\right)$, Co-Raney form $\left(53.70 \mathrm{~kJ} \cdot \mathrm{mol}^{-1}\right)$, and active carbon supported Co-B $\left(57.80 \mathrm{~kJ} \cdot \mathrm{mol}^{-1}\right)$ were relatively higher than our results, while Co nanoparticle $\left(35.00 \mathrm{~kJ} \cdot \mathrm{mol}^{-1}\right)$ was lower. The hydrolysis of alkaline $\mathrm{NaBH}_{4}$ solution was carried out with sonochemical approach, the reaction kinetic was improved and value of them was decreased up to $12 \%$.
TABLE 3: Activation energies in presence of various Co-based catalysts.

\begin{tabular}{lcc}
\hline Catalyst & $\begin{array}{c}\text { Activation energy } \\
\left(\mathrm{kJ} \cdot \mathrm{mol}^{-1}\right)\end{array}$ & References \\
\hline Co powder & 75.00 & {$[31]$} \\
Co nanoparticle & 35.00 & {$[13]$} \\
Co $\left(\alpha-\mathrm{Al}_{2} \mathrm{O}_{3}\right.$ support) & 32.63 & {$[32]$} \\
Co (Raney form) & 53.70 & {$[33]$} \\
Co-B (active carbon support) & 57.80 & {$[34]$} \\
Co-B powder & 64.87 & {$[12]$} \\
Co-B (clay support) & 56.32 & {$[35]$} \\
Co-B & 52.73 & {$[36]$} \\
CoB-1 (sonohydrolysis) & 46.15 & At this \\
CoB-1 (magnetic stirring & 51.68 & work \\
hydrolysis) & At this \\
\hline
\end{tabular}

\section{Conclusion}

In the present study, sonochemical approach to coprecipitation synthesis of Co-B catalyst and hydrolysis of alkaline $\mathrm{NaBH}_{4}$ solutions was introduced. The following points result from this study.

The sono-co-precipitation of $\mathrm{CoCl}_{2} \cdot 6 \mathrm{H}_{2} \mathrm{O}$ and $\mathrm{B}_{2} \mathrm{O}_{3}$ in aqueous solution at $\mathrm{pH} 6$ was proven to be a promising procedure in order to obtain Co-B crystalline catalyst with uniform $1.25 \mu \mathrm{m}$ particle size, improved surface area, and texture properties. On the other hand, it was found that sonochemical approach did not affect the crystalline structure and spectral properties of Co-B catalyst yet.

The improving effect of sonochemical process on hydrolysis of alkaline $\mathrm{NaBH}_{4}$ solutions was approved when it was compared with magnetic stirring system kinetic results. Hydrogen generation rate of alkaline $\mathrm{NaBH}_{4}$ solutions via sonohydrolysis method in presence of CoB-1 catalyst has shown enhanced influence at all temperatures. Activation energy as $46.15 \mathrm{~kJ} \cdot \mathrm{mol}^{-1}$ of sonochemical coprecipitation synthesized Co-B catalyst has compatible value compared with literature $\left(32-75 \mathrm{~kJ} \cdot \mathrm{mol}^{-1}\right)$. Rate law was formulized as given below:

$$
r_{\mathrm{NaBH}_{4}}=19.89 \cdot e^{-46.15 / \mathrm{RT}} .
$$

As a result of this study, the ultrasonic waves improved the intrinsic and extrinsic properties of Co-B catalyst properties as specific surface area increased up to $70 \%$, particle size decreased up to $58 \%$, and hydrogen generation rate increased up to $64 \%$. As can be seen, sonochemical coprecipitation and sonohydrolysis proved to be promising techniques for synthesis of Co-B catalyst and hydrolysis. 

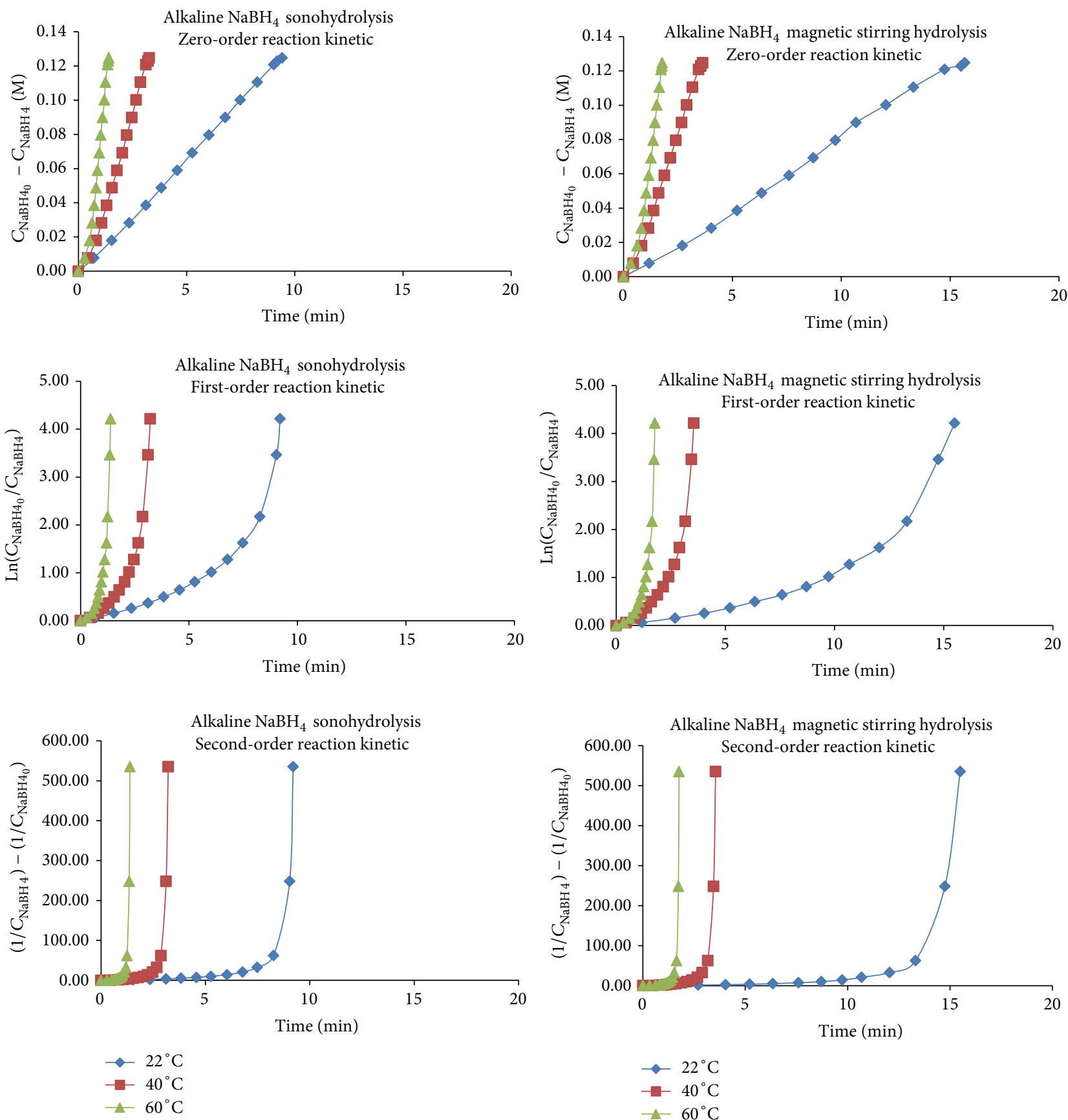

Figure 7: The kinetic investigation: the zero, first, and second reaction kinetic models for sonohydrolysis and magnetic stirring hydrolysis of alkaline (10 wt.\%) $0.12 \mathrm{M} \mathrm{NaBH}_{4}$ solutions.

\section{Symbols Used}

$r: \quad\left[\mathrm{H}_{2} \mathrm{~mol} \cdot \mathrm{min}^{-1} \cdot \mathrm{g}^{-1} \mathrm{cat}\right] \mathrm{H}_{2}$ generation rate

$E_{a}:\left[\mathrm{kJ} \cdot \mathrm{mol}^{-1}\right]$ Activation energy

$R:\left[\mathrm{kJ} \cdot \mathrm{mol}^{-1} \cdot{ }^{\circ} \mathrm{C}^{-1}\right]$ Gas constant

T: $\left[{ }^{\circ} \mathrm{C}\right]$ Temperature.

\section{Conflict of Interests}

The authors declare that there is no conflict of interests regarding the publication of this paper.

\section{Acknowledgments}

The authors would like to thank the Yildiz Technical University Research Foundation (Project no.: 2012-07-01-YL02) for its financial support.

\section{References}

[1] S. C. Amendola, S. L. Sharp-Goldman, M. S. Janjua et al., "Safe, portable, hydrogen gas generator using aqueous borohydride solution and Ru catalyst," International Journal of Hydrogen Energy, vol. 25, no. 10, pp. 969-975, 2000. 
[2] R. Retnamma, A. Q. Novais, and C. M. Rangel, "Kinetics of hydrolysis of sodium borohydride for hydrogen production in fuel cell applications: a review," International Journal of Hydrogen Energy, vol. 36, no. 16, pp. 9772-9790, 2011.

[3] O. Akdim, U. B. Demirci, D. Muller, and P. Miele, "Cobalt (II) salts, performing materials for generating hydrogen from sodium borohydride," International Journal of Hydrogen Energy, vol. 34, no. 6, pp. 2631-2637, 2009.

[4] J. Liang, Y. Li, Y. Huang et al., "Sodium borohydride hydrolysis on highly efficient $\mathrm{Co}-\mathrm{B} / \mathrm{Pd}$ catalysts," International Journal of Hydrogen Energy, vol. 33, no. 15, pp. 4048-4054, 2008.

[5] U. B. Demirci, O. Akdim, J. Andrieux, J. Hannauer, R. Chamoun, and P. Miele, "Sodium borohydride hydrolysis as hydrogen generator: Issues, state of the art and applicability upstream froma fuel cell," Fuel Cells, vol. 10, no. 3, pp. 335-350, 2010.

[6] U.S. Department of Energy Hydrogen Program, 2007, http://www.hydrogen.energy.gov/.

[7] U. B. Demirci and P. Miele, "Sodium borohydride versus ammonia borane, in hydrogen storage and direct fuel cell applications," Energy and Environmental Science, vol. 2, no. 6, pp. 627-637, 2009.

[8] B. H. Liu and Z. P. Li, "A review: Hydrogen generation from borohydride hydrolysis reaction," Journal of Power Sources, vol. 187, no. 2, pp. 527-534, 2009.

[9] S. Cavaliere, J. Hannauer, U. B. Demirci, O. Akdim, and P. Miele, "Ex situ characterization of $\mathrm{N}_{2} \mathrm{H}_{4}^{-}, \mathrm{NaBH}_{4}$ - and $\mathrm{NH}_{3} \mathrm{BH}_{3}$ reduced cobalt catalysts used in $\mathrm{NaBH}_{4}$ hydrolysis," Catalysis Today, vol. 170, no. 1, pp. 3-12, 2011.

[10] H. I. Schlesinger, E. R. Brown, A. E. Finholitam, J. R. Gilbreathh, H. R. Hoekstra, and E. A. Hyde, "Procedures for the preparation of methyl borate," Journal of American Chemical Society, vol. 75, no. 1, pp. 213-215, 1953.

[11] A. M. Ozerova, V. I. Simagina, O. V. Komova et al., "Cobalt borate catalysts for hydrogen production via hydrolysis of sodium borohydride," Journal of Alloys and Compounds, vol. 513, pp. 266-272, 2012.

[12] S. U. Jeong, R. K. Kim, E. A. Cho et al., "A study on hydrogen generation from $\mathrm{NaBH}_{4}$ solution using the high-performance Co-B catalyst," Journal of Power Sources, vol. 144, no. 1, pp. 129134, 2005.

[13] R. Khan, S. W. Kim, T.-J. Kim, and C.-M. Nam, "Comparative study of the photocatalytic performance of boron-iron Codoped and boron-doped $\mathrm{TiO}_{2}$ nanoparticles," Materials Chemistry and Physics, vol. 112, no. 1, pp. 167-172, 2008.

[14] A. Kantürk Figen and B. Coşkuner, "A novel perspective for hydrogen generation from ammonia borane $\left(\mathrm{NH}_{3} \mathrm{BH}_{3}\right)$ with Co-B catalysts: 'ultrasonic Hydrolysis,' International Journal of Hydrogen Energy, vol. 38, no. 6, pp. 2824-2835, 2013.

[15] C. C. Yang, M. S. Chen, and Y. W. Chen, "Hydrogen generation by hydrolysis of sodium borohydride on $\mathrm{CoB} / \mathrm{SiO}_{2}$ catalyst," International Journal of Hydrogen Energy, vol. 36, no. 2, pp. 14181423, 2011.

[16] R. Patil, P. Bhoir, P. Deshpande, T. Wattamwar, M. Shirude, and P. Chaskar, "Relevance of sonochemistry or ultrasound (US) as a proficient means for the synthesis of fused heterocycles," Ultrasonics Sonochemistry, vol. 20, no. 6, pp. 1327-1336, 2013.

[17] T. Q. Liu, O. Sakurai, N. Mizutani, and M. Kato, "Preparation of spherical fine $\mathrm{ZnO}$ particles by the spray pyrolysis method using ultrasonic atomization techniques," Journal of Materials Science, vol. 21, no. 10, pp. 3698-3702, 1986.
[18] S. L. Che, K. Takada, K. Takashima, O. Sakurai, K. Shinozaki, and N. Mizutani, "Preparation of dense spherical Ni particles and hollow $\mathrm{NiO}$ particles by spray pyrolysis," Journal of Materials Science, vol. 34, no. 6, pp. 1313-1318, 1999.

[19] C. L. Bianchi, E. Gotti, L. Toscano, and V. Ragaini, "Preparation of Pd/C catalysts via ultrasound: a study of the metal distribution," Ultrasonics Sonochemistry, vol. 4, no. 4, pp. 317-320, 1997.

[20] S. S. Ostapenko, L. Jastrzebski, J. Lagowski, and B. Sopori, "Increasing short minority carrier diffusion lengths in solargrade polycrystalline silicon by ultrasound treatment," Applied Physics Letters, vol. 65, no. 12, pp. 1555-1557, 1994.

[21] M. Run, S. Wu, and G. Wu, "Ultrasonic synthesis of mesoporous molecular sieve," Microporous and Mesoporous Materials, vol. 74, no. 1-3, pp. 37-47, 2004.

[22] U. R. Pillai, E. Sahle-Demessie, and R. S. Varma, "Alternative routes for catalyst preparation: use of ultrasound and microwave irradiation for the preparation of vanadium phosphorus oxide catalyst and their activity for hydrocarbon oxidation," Applied Catalysis A: General, vol. 252, no. 1, pp. 1-8, 2003.

[23] H. Li, H. Li, J. Zhang, W. Dai, and M. Qiao, "Ultrasound-assisted preparation of a highly active and selective Co-B amorphous alloy catalyst in uniform spherical nanoparticles," Journal of Catalysis, vol. 246, no. 2, pp. 301-307, 2007.

[24] M. G. Sulman, "Effects of ultrasound on catalytic processes," Russian Chemical Reviews, vol. 69, no. 2, pp. 165-177, 2000.

[25] H. Li, J. Zhang, and H. Li, "Ultrasound-assisted preparation of a novel Ni-B amorphous catalyst in uniform nanoparticles for p-chloronitrobenzene hydrogenation," Catalysis Communications, vol. 8, no. 12, pp. 2212-2216, 2007.

[26] A. J. Hung, S. F. Tsai, Y. Y. Hsu, J. R. Ku, Y. H. Chen, and C. C. Yu, "Kinetics of sodium borohydride hydrolysis reaction for hydrogen generation," International Journal of Hydrogen Energy, vol. 33, no. 21, pp. 6205-6215, 2008.

[27] O. Levenspiel, Chemical Reaction Engineering, John Wiley \& Sons, New York, NY, USA, 3rd edition, 1999.

[28] L. Jun, X. Shuping, and G. Shiyang, "FT-IR and Raman spectroscopic study of hydrated borates," Spectrochimica Acta A: Molecular Spectroscopy, vol. 51, no. 4, pp. 519-532, 1995.

[29] A. Kanturk, M. Sari, and S. Piskin, "Synthesis, crystal structure and dehydration kinetics of $\mathrm{NaB}(\mathrm{OH})_{4} \cdot 2 \mathrm{H}_{2} \mathrm{O}$," Korean Journal of Chemical Engineering, vol. 25, no. 6, pp. 1331-1337, 2008.

[30] Q. Zhang, Y. Wu, X. Sun, and J. Ortega, "Kinetics of catalytic hydrolysis of stabilized sodium borohydride solutions," Industrial and Engineering Chemistry Research, vol. 46, no. 4, pp. 1120-1124, 2007.

[31] J. Andrieux, D. Swierczynski, L. Laversenne et al., "A multifactor study of catalyzed hydrolysis of solid $\mathrm{NaBH}_{4}$ on cobalt nanoparticles: thermodynamics and kinetics," International Journal of Hydrogen Energy, vol. 34, no. 2, pp. 938-951, 2009.

[32] B. H. Liu, Z. P. Li, and S. Suda, "Nickel- and cobalt-based catalysts for hydrogen generation by hydrolysis of borohydride," Journal of Alloys and Compounds, vol. 415, no. 1-2, pp. 288-293, 2006.

[33] W. Ye, H. Zhang, D. Xu, L. Ma, and B. Yi, "Hydrogen generation utilizing alkaline sodium borohydride solution and supported cobalt catalyst," Journal of Power Sources, vol. 164, no. 2, pp. 544548, 2007.

[34] J. Zhao, H. Ma, and J. Chen, "Improved hydrogen generation from alkaline image solution using carbon-supported image as catalysts," International Journal of Hydrogen Energy, vol. 32, no. 18, pp. 4711-4716, 2007. 
[35] H. Tian, Q. Guo, and D. Xu, "Hydrogen generation from catalytic hydrolysis of alkaline sodium borohydride solution using attapulgite clay-supported Co-B catalyst," Journal of Power Sources, vol. 195, no. 8, pp. 2136-2142, 2010.

[36] C. H. Liu, B. H. Chen, C. L. Hsueh, J. R. Ku, M. S. Jeng, and F. Tsau, "Hydrogen generation from hydrolysis of sodium borohydride using Ni-Ru nanocomposite as catalysts," International Journal of Hydrogen Energy, vol. 34, no. 5, pp. 2153-2163, 2009. 

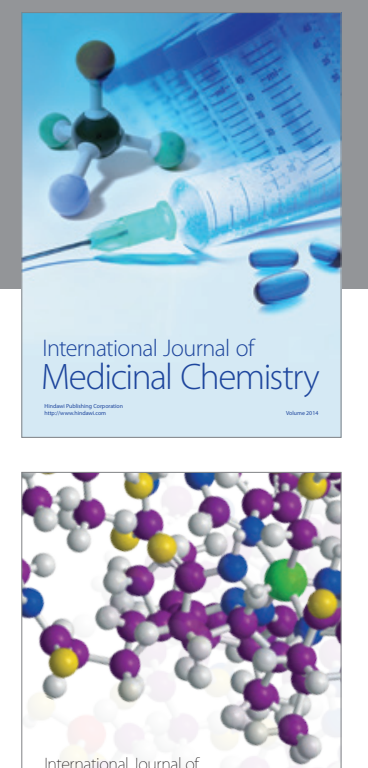

\section{Carbohydrate} Chemistry

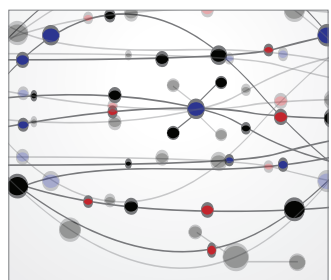

The Scientific World Journal
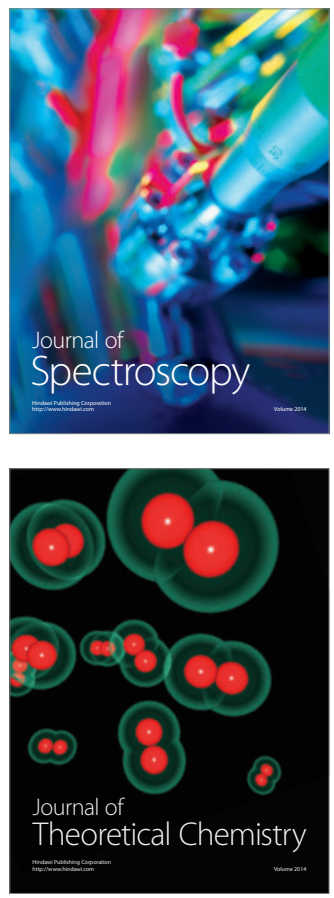
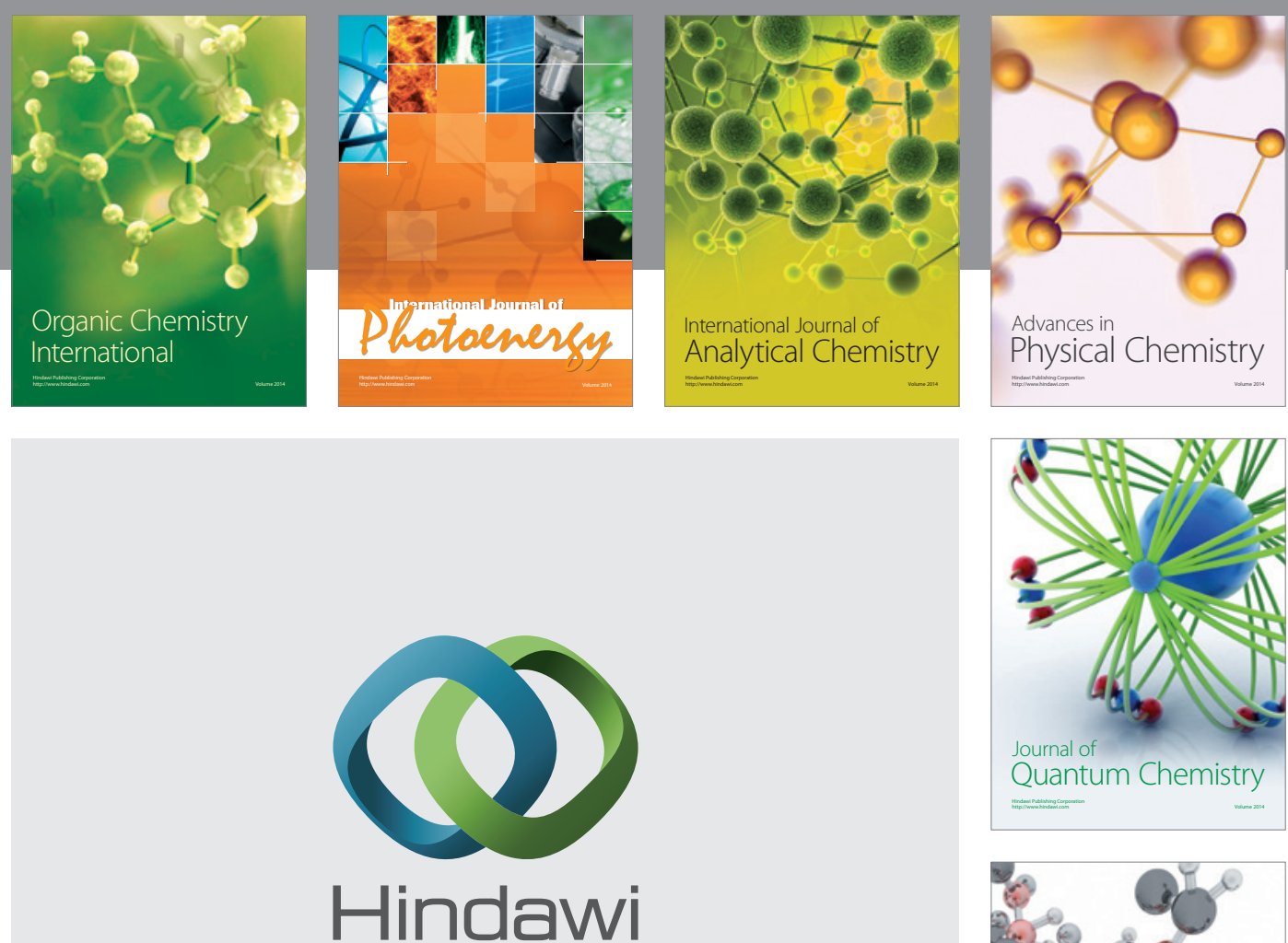

Submit your manuscripts at

http://www.hindawi.com

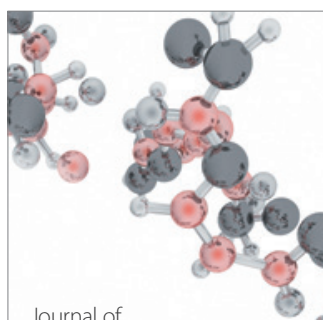

Analytical Methods

in Chemistry

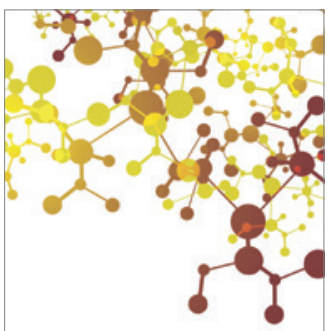

Journal of

Applied Chemistry

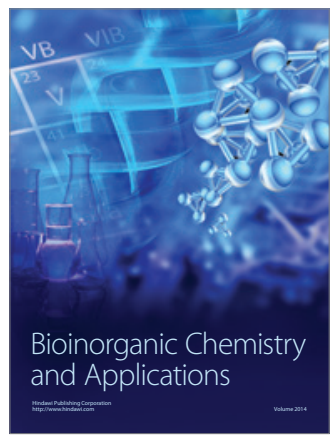

Inorganic Chemistry
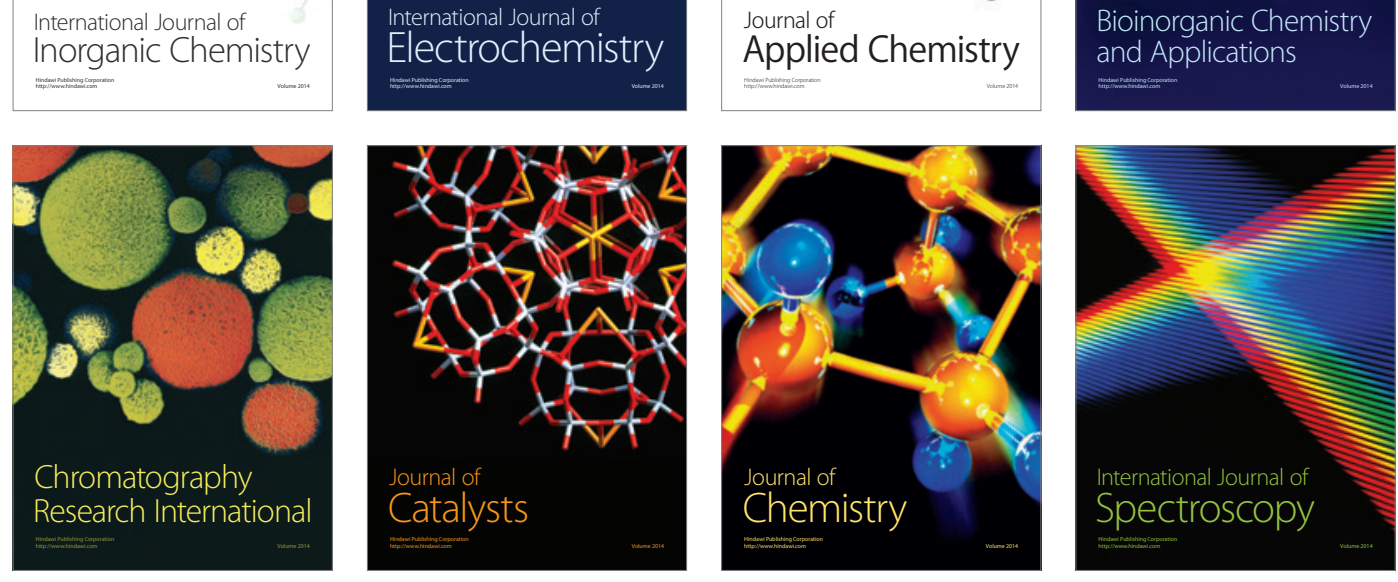